\title{
1. Standing on the shoulders of giants
}

Appreciation of Schumpeterian literature has been quite selective. The 1911 book The Theory of Economic Development and the 1942 Capitalism Socialism and Democracy have attracted much attention, and actually exhausted it. Other relevant Schumpeterian contributions have been gradually forgotten. The crucial essay 'The creative response in economic history' published in the Journal of Economic History in 1947 received little attention after its publication, and has been largely forgotten since then. ${ }^{1}$ According to the Social Science Indicator, the essay received no citations in the time span 1985-2012. The other contributions and mainly the two books by Schumpeter received a total of 2400 citations in the same time interval.

This exclusion impedes the correct appreciation of the evolution of the Schumpeterian analysis of the role of innovation in economic growth. It also deprives economics of a framework that can accommodate in a more inclusive approach the important tools of analysis elaborated by Schumpeter in almost 40 years of activity dedicated to grasping the role of innovation in the economy and in economics. The aim of this section is twofold:

- to highlight the merits of Schumpeter's 1947 essay, articulating the view that it should be considered the result of his successful attempt to synthesize, into a single integrated and coherent framework the main results of his life work on the role of innovation in the economy and in economics;

- to show how the notion of innovation as the result of a creative reaction, conditional on the characteristics of the system, provides the foundations for new understanding of innovation as an emergent property of system dynamics.

This framework enables us to identify the limitations of the main approaches to explaining innovation and technological change, and to appreciate the contributions of the Marshallian legacy.

The new growth theory and the evolutionary approach are the two competing frameworks available in the current literature to study the economic 
determinants of innovation. They have provided the basic ingredients for an endogenous theory of innovation. Identification of the central relationship between the early economics of knowledge and the economics of growth is the main contribution of the new growth theory. The central role of the variety of innovations being introduced at each point in time is the main contribution of evolutionary approaches. They provide the indispensable background for any attempt to elaborate solid microfoundations of the innovation process. The limits of both approaches, however, have become more and more evident.

\subsection{THE LIMITS OF THE NEW GROWTH THEORY}

The new growth theory impinges upon the results of the preliminary steps of the economics of knowledge to elaborate an endogenous account of economic growth. It builds upon the results of the enquiry into the economic properties of knowledge as an economic good. Technological knowledge is characterized by limited appropriability that has the twin effect of reducing the revenue that 'inventors' can earn from its generation and - spilling through the system - reducing the costs of its generation for anybody else in the system. The non-excludable component of new technological knowledge generated at each point in time contributes directly to the increase of total factor productivity (TFP) at the system level: knowledge plays a central role as the engine of growth (Romer, 1990, 1994a, b, 2015).

The elegant and articulated frame of the new growth theory justified its success and stirred a variety of applications and empirical tests that gradually questioned its foundations. It became clearer and clearer that the new growth theory was unable to cope with the strong and shared evidence about the huge variance of total factor productivity levels and rates of increase across agents, industries, regions, countries and, most importantly, historic times (Craft, 2010).

The recent advances of new economics of knowledge, especially at the microeconomic level, questioned some of its basic assumptions. First, it became apparent that the new growth theory rested upon quite an implicit postulate about a positive sum game between the effects of the excludable and non-excludable components of technological knowledge. The new growth theory, as a matter of fact, does not provide a clear analysis of the reasons why the losses that 'inventors' suffer from the lack of appropriation of the non-excludable part of the knowledge they contributed to fund should be lower than the benefits in terms of increased total factor productivity. Actually, at the microeconomic level, it is difficult to understand 
why a firm should experience an increase in total factor productivity stemming from expenses that have been made without any benefit in terms of revenue. Moreover, the microeconomics of knowledge suggests that, even with a positive-sum game, the new growth theory does not provide any clue to understanding how and why opportunistic behaviour should not prevail. Even when the Romer postulate of a positive-sum game applies, in fact, each firm misses the appropriate incentives to invest resources in the generation of knowledge. The argument is stronger with a non-positive sum game, either zero or negative: firms have no incentive to invest resources in the generation of new knowledge. According to the recent advances in the microeconomics of knowledge, the new growth theory is unable to avoid the implications of Arrovian analysis of the negative effects of knowledge non-appropriability. ${ }^{2}$

A second bundle of problems about the limits of the assumptions of the new growth theory - that spillovers engender pure and instantaneous knowledge externalities that can be absorbed and used at no costs - became progressively clear. Recent advances in the new economics of knowledge have explored the effects of knowledge cumulability, complementarity and non-exhaustibility. They have also made clear the role of the stock of knowledge - both internal and external to each firm - in the recombinant generation of new technological knowledge. Technological knowledge is at the same time an input and an output characterized by high levels of tacitness that make access to and use of external knowledge difficult.

Agents can benefit from knowledge externalities only after appropriation lags and substantial efforts to screen, identify, absorb and recombine external knowledge as an input into the generation of new knowledge. Knowledge externalities are diachronic and pecuniary: first, knowledge appropriability is transient rather than partial. Technological knowledge can be appropriated by 'inventors' for a limited but qualified stretch of time. It becomes a public good only after some time. The flows of knowledge generated at each point in time add to the stock of public knowledge only through time. As such, knowledge externalities are diachronic as opposed to synchronic. Second, the absorption and eventual use of selected knowledge items extracted from the stock of public knowledge requires efforts and resources. External knowledge is not free. It has a cost that is lower than the cost of first generation. As such, knowledge externalities are pecuniary, as opposed to pure.

Third, the evidence confirms that innovation takes place in highly idiosyncratic conditions, with huge variance across agents, industries, regions and historic times. This evidence contradicts the assumptions of new growth theory that innovation is spontaneous, unlimited, ubiquitous and evenly distributed in time and space. 
Finally, the limits of the implicit assumption that technological knowledge and technological innovation coincide seem more and more evident. The availability of knowledge externalities and, more generally, the idiosyncratic characteristics of knowledge are not sufficient to understand why firms do innovate. Knowledge externalities, in other words, are indeed a necessary condition for innovation to take place, but not a sufficient one. Firms are reluctant to introduce innovations, and they can actually innovate only when a number of complementary conditions apply. Knowledge externalities are part of the set of conditions upon which innovation is contingent, but they are not the single and most exclusive factor.

As a consequence, externalities are not only diachronic and pecuniary, but also stochastic (localized in time and space) rather than synchronic, pure or technical (ubiquitous in time and space and automatic). Structured interactions are necessary to use knowledge spillovers as inputs in the recombinant generation of new technological knowledge. Highly localized and specific circumstances make available external knowledge that can be accessed and used at costs that are below equilibrium levels. Knowledge externalities, moreover, are a necessary but not sufficient condition for the actual introduction of innovations and the consequent increase of total factor productivity (Antonelli and David, 2015).

\subsection{THE LIMITS OF BIOLOGICAL EVOLUTIONARY APPROACHES}

Different waves of evolutionary frameworks have been elaborated since the founding contribution of Thorstein Veblen (1898) focused on the role of heterogeneity of agents and institutions. After the decline of the second framework by Armen Alchian (1950), centred primarily on the role of uncertainty, evolutionary economics was revived at the end of the twentieth century by Richard Nelson and Sidney Winter with the grafting of biological metaphors. This (third) approach emphasizes the role of innovations, and made crucial contributions to understanding industrial dynamics based on the selective adoption and imitation of innovations. This evolutionary framework explores the effects of the exogenous introduction of a variety of innovations and their sequential and cumulative selection on the dynamics of market shares of firms and aggregate growth. The introduction of innovations, however, is assumed to be automatic and random. Biological evolutionary models pay very little attention to the endogenous determinants of innovation.

Evolutionary approaches that build upon the path-breaking contributions of Nelson and Winter (1982) have renewed the Schumpeterian 
centrality of innovation in economic theory, and shown that economic systems are characterized by perennial change both in technology and structure. To elaborate their framework, Nelson and Winter rely on Darwinistic metaphors according to which agents try to change their routines only as a reaction to adversity. ${ }^{3}$ In the rest of their 1982 book, however, Nelson and Winter suggest that firms change their routines and introduce innovations without a specific cause. Firms learn and occasionally change their routines; but it is not clear why firms would feel the need to change. Their changes are sorted out in the selection environment: some survive and are adopted. Many fail. Occasionally firms have the chance to introduce innovations - that is, new and superior technologies: as a matter of fact innovation is random and exogenous. ${ }^{4}$ Innovation is, in fact, the ex post result of the selection process.

The standard evolutionary approach misses serious microeconomic foundations of the introduction of innovations. Standard evolutionary economics has made crucial contributions to the understanding of industrial dynamics based upon the selective adoption and imitation of innovations. The standard evolutionary framework explores the effects of the exogenous introduction of a variety of innovations and their sequential and cumulative selection on the dynamics of market shares of firms and aggregate growth. The introduction of innovations, in fact, is assumed to be automatic and random.

The attempt to rely upon metaphors elaborated in biology to understand the evolution of economic systems can be regarded as the main cause of the weak microeconomic foundations of standard evolutionary thinking. As Edith Penrose $(1952,1953)$ had already remarked more than 30 years before the publication of An Evolutionary Theory of Economic Change (Nelson and Winter, 1982):

To treat the growth of the firm as the unfolding of its genetic nature is downright obscurantism. To treat innovations as chance mutations not only obscures their significance but leaves them essentially unexplained, while to treat them directly as purposive attempts of men to do something makes them far more understandable. To draw an analogy between genetic heredity and the purposive imitation of success is to imply that in biology the characteristics acquired by one generation in adapting to its environment will be transmitted to future generations. This is precisely what does not happen in biological evolution. Even as a metaphor it is badly chosen although in principle metaphorical illustrations are legitimate and useful. But in seeking the fundamental explanations of economic and social phenomena in human affairs the economist, and the social scientist in general, would be well advised to attack his problems directly and in their own terms rather than indirectly by imposing sweeping biological models upon them. (Penrose, 1952: 819) 
As a matter of fact, standard evolutionary thinking suffers all the ambiguities of the confusion between Jean-Baptiste Lamarck - revived for economics after his dismissal from biology - and Charles Darwin. According to Lamarck, the evolution of species is the result of the intentional changes made by the individual in behaviour (phenotype) to cope with adverse changes in the environment. Changes in phenotype would eventually lead to changes in genotypes. The changes in genotypes would in turn yield mutation and speciation. Mutation is fully endogenous: as such far from random and actually the outcome of an intentional action and a clear cause. Charles Darwin showed that changes in phenotype cannot yield eventual changes in genotype, and could be transmitted. Mutation and eventual speciation are the outcomes of random variations that are generated by chance. Each variation retains a change in genotype. Out of the many novelties, the selection process is able to select those that are better able to fit in the changing environment. Selection is endogenous, while mutation is exogenous.

The attempt of evolutionary economics to borrow from biological evolution has taken place with substantial ambiguity, contradiction and confusion. The grafting of the Lamarckian hypothesis requires causality: firms change behaviour (phenotypes) because of specific economic circumstances that affect their performances. The revival of the Lamarckian hypothesis leads to the failure inducement hypothesis. Innovations are introduced to cope with performances that fall below some 'satisficing' level. The grafting of the Darwinian hypothesis, on the contrary, requires that mutation is random and exogenous. Selection is endogenous, but innovation is not.

Standard evolutionary approaches suffer the contradiction between these two approaches that has never been solved. The ambiguity dates back to the founding contribution of Nelson and Winter (1982) in An Evolutionary Theory of Economic Change. Careful reading of their book reveals substantial ambiguity between two specifications: i) firms try to search for technological changes (innovations) randomly; ii) firms try to search for technological changes when their performance falls below a satisficing level. Nelson and Winter never acknowledge the contradiction between these suggestions and in their book never try to articulate a solution. They let the alternatives coexist. As a matter of fact Nelson and Winter swing between the grafting of the Lamarckian metaphor and the Darwinistic one without understanding their inconsistency. Let us explore them in depth.

\section{Innovation as a Random Event}

Firms are constantly searching for new and better technologies. Firms are not risk averse. They are ready to bear the risks associated with the 
introduction of innovations at all times and in all circumstances, irrespective of their profitability levels. They rely on automatic learning processes. Learning processes enable the accumulation of tacit knowledge. The stock of tacit knowledge keeps increasing, and firms keep searching. Nelson and Winter are very clear on this:

In the orthodox formulation, the decision rules are assumed to be profitmaximizing over a sharply defined opportunity set that is taken as a datum, the firms in the industry and the industry as a whole are assumed to be at equilibrium size, and innovation (if treated at all) is absorbed into the traditional framework rather than mechanically. In evolutionary theory, decision rules are viewed as a legacy from firm's past and hence appropriate, at best, to the range of circumstances in which the firm customarily finds itself, and are viewed as unresponsive, or inappropriate to novel situations or situations encountered irregularly. Firms are regarded as expanding or contracting in response to disequilibria, with no presumption that the industry is 'near' equilibrium. Innovation is treated as stochastic and as variable across firms. (Nelson and Winter, 1982: 165-6)

According to them, innovation takes place as a random process. Incumbents keep changing their routines, and occasionally have the chance to introduce actual innovations - i.e. new, superior technologies. Innovation is neither determined by intentional action nor by the properties of the system. Firms that have been 'lucky' will introduce successful innovations that are adopted because they fit the changing environment. Firms do not have a strategy and a project

As a matter of fact Nelson and Winter rely on an implicit postulate according to which homo oeconomicus is characterized by the spontaneous propensity to innovate. Yet their postulate about the spontaneous drive to change routine and introduce, occasionally, better technologies that are ex post sorted out in the eventual selection process does not find the necessary support in the economics of decision-making. Agents are reluctant to make all the efforts that are necessary to innovate, for two basic reasons: first, the innovation process is characterized by radical uncertainty. Its outcome and timing cannot be predicted; second, because of limited appropriability and tradability, the economic exploitation of innovations is itself characterized by radical uncertainty. Agents need a specific motivation to try to innovate that goes beyond the need to cope with adversity and include the 'Schumpeterian' hypothesis (1942) that profits above the average feed the innovation process. Yet the large literature that builds upon the contributions by Nelson and Winter $(1973,1982)$ consistently does not provide a clue to understanding why firms innovate. Once again the assumptions on which Nelson and Winter elaborate their Darwinistic approach imply that innovation should take place evenly across agents through time and space. 
As a matter of fact it seems difficult to distinguish the innovation process portrayed by the evolutionary approaches that impinge upon the legacy of Nelson and Winter from the 'manna' of the neoclassic theory of growth so much criticized. Neither the manna nor this evolutionary approach here is able to justify the huge variance in the distribution of actual innovation processes. Substantial evidence shows that some agents innovate more than others, some regions innovate more than others and some industries are more innovative than others: innovations cluster in time and space.

This approach impinges upon the line of analysis that pays attention to learning processes. The accumulation of competence is the outcome of learning. The introduction of innovations relies on the accumulation of tacit knowledge made possible by means of learning processes. This approach is not able to cope with the large body of evidence on the large variance among firms in terms of rates of introduction of successful innovations. It seems that some firms are better able to learn than others. This raises in turn the issue of what are the determinants of such variance. The emphasis on the role of randomness and chance seems to be the result of a clear analytical dead end. ${ }^{5}$

\section{Innovation When Performance Level Falls}

The alternative failure-inducement hypothesis is well articulated by Nelson and Winter (1982: 211) as follows:

we assume that if firms are sufficiently profitable they do no 'searching' at all. They simply attempt to preserve their existing routines, and are driven to consider alternatives only under the pressure of adversity. Their R\&D activity should thus be conceived as representing an ad hoc organizational response rather than a continuing policy commitment. This satisficing assumption is a simple and extreme representation of the incentives affecting technical change at the firm level.

In the failure-inducement hypothesis innovation is introduced only as a response to performances that fall below some satisficing level.

It seems clear that both the view that innovation is automatic and random and the failure-inducement hypothesis are at odds with the Schumpeterian literature. More specifically, the failure-inducement hypothesis contrasts sharply with both Schumpeter's (1942) analysis and the neo-Schumpeterian literature. According to Schumpeter, innovation is made possible by the accumulation of extra profits that stem from the appropriation of the rents that are engendered by the introduction of innovations. The longer the time span of appropriation, the faster the rates of introduction. The so-called Schumpeterian hypothesis has been the 
mother's milk of the rich neo-Schumpeterian literature that has explored the relationship between market structure, appropriability regimes, profitability and rates of introduction of innovation. The well-known conclusion has been that temporary monopolies can increase welfare because they empower the virtuous mechanism by means of which innovations breed innovations (Scherer, 1986). The microfoundations of the innovation process of the standard evolutionary approach are clearly contradictory and inconsistent with the Schumpeterian legacy.

The evolutionary literature that impinges upon the path-breaking contribution of Nelson and Winter abandons the failure inducement hypothesis. Instead, it fully retains their basic assumption that the introduction of innovations is a spontaneous and automatic process that is not characterized by intentionality and has no microeconomic foundation. The strength of this literature lies in its path-breaking analysis of the diffusion of innovations as the outcome of a selection mechanism that, out of the many innovations introduced randomly, is able to sort those that fare better. The selection mechanism is, instead, fully endogenous and allows sorting innovations, out of the many attempts, that fit better the system. ${ }^{6}$ In the models of industrial dynamics, innovation is exogenous while diffusion is endogenous.

The history-friendly models elaborated by Malerba et al. (1999, 2001) simply assume that some firms innovate:

At the beginning of our episode, the only available technology for computer designs is transistors. $N$ firms engage in efforts to design a computer, using funds provided by 'venture capitalists' to finance their R\&D expenditures. Some firms succeed in achieving a computer that meets a positive demand and begin to sell. This way they first break into the mainframe market. Some other firms exhaust their capital endowment and fail. Firms with positive sales use their profits to pay back their initial debt, to invest in R\&D and in marketing. With R\&D activity firms acquire technological competencies and become able to design better computers. Different firms gain different market shares, according to their profits and their decision rules concerning pricing, $\mathrm{R} \& \mathrm{D}$ and advertising expenditure. Over time firms come closer to the technological frontier defined by transistor technology, and technical advance becomes slower. (Malerba et al., 2001: 4-5)

In history-friendly models the microeconomic decision of whether or not to innovate is completely missing. Innovation is assumed as a given characteristic of the system.

The influential contributions of Iwai $(1984,2000)$ make this point very clearly: the analysis moves from the assumption that an innovation has been introduced. It does not explore who did try to innovate, or why, when and where. Iwai's analysis of the characteristics of the selective diffusion of 
many competing technologies remains one of the key contributions of the standard evolutionary literature.

The inclusive review of the evolutionary literature of Safarzyńska and van den Bergh (2010: 347) concludes that:

\begin{abstract}
Although innovations are intrinsically uncertain, and for this reason in most evolutionary-economic models treated as stochastic, it would be incorrect to consider the process of innovation as totally random. Innovations may be expected to occur in a systematic manner, namely preceded by the cumulativeness of relevant technical advances. The innovative process is often depicted as following relatively ordered technological path-ways, as is reflected by notions such as natural trajectories (Nelson and Winter 1977), technological guide points (Sahal 1985), technological paradigms (Dosi 1982), and sociotechnological regimes (Geels 2002, 2005). Innovations are conceptualized in formal models in a number of ways: as a stochastic process (e.g., Poisson) that can result in structural discontinuity, variation and recombination of existing technological options, or random or myopic search on a fitness (technology) landscape. Innovations may be associated with a new vintage of capital (e.g., Iwai 1984a, b; Silverberg and Lehnert 1993; Silverberg and Verspagen 1994a, b, 1995). 'Standard evolutionary theory misses an agent based theory of innovation'.
\end{abstract}

The models of industrial dynamics that impinge upon the basic contribution of Dosi et al. (1995) assume that innovations are determined by technological opportunities; but no analysis is provided of the specific characteristics of the decision process at firm level: all firms are expected to innovate when, where and if technological opportunities are at large. The determinants of technological opportunities are missing; as such they must be regarded as exogenous.

The important contribution by Winter et al. (2000) explores an alternative route: innovation is the direct and automatic consequence of learning. Learning processes are deemed to engender the accumulation of technological knowledge and the eventual introduction of innovations. The introduction of innovations is simply the consequence of learning processes: as such they take place at all times, in all conditions and in all locations. There is no variety in these models with respect to the innovation process: all firms do learn and do innovate. The possibility that some firms innovate (more) and others do not is not taken into account.

Windrum and Birchenhall (2005) provide the basic reference for the analysis of the models of selective adoption and implementation. They highlight the role of network externalities in the selection of alternative (given) technological innovations. For a given set of potential technologies, network externalities play a critical role in sorting out those that have stronger chances of further development and implementation. Once more the analysis does not take into account the determinants of the process by which agents tried to 
introduce each of the many alternative innovations. The variety of possible technological innovations is assumed but not explained.

As Dawid (2006) shows in his comprehensive review of the evolutionary models of innovation and technological change that impinge upon the agent-based approach, the decision to innovate is little explored: the focus of the analytical exploration is concentrated on the characteristics of the selective diffusion process rather than on the determinants of the innovation process.

The microeconomic limits of the standard evolutionary approach are becoming more and more evident. The empirical evidence documents the large variance among firms in terms of rates of introduction of innovations as proxied by $R \& D$ expenditure and intensity, patents, total factor productivity levels and innovation counts, and calls for an effort to build consistent microfoundations of innovation.

Standard evolutionary theorizing seems to be trapped in its Darwinistic analogy where, as a matter of fact, variation is fully random and exogenous. Changes in genotype cannot be intentional, and do take place by chance. The characteristics of the new species do not reflect the purposes of their relatives. Instead, their selection is endogenous as, out of the many variations, it enables identification of those that fit better into the environment. The grafting of the Darwinistic analogy onto economics impedes understanding of the determinants of the introduction of innovations at the firm level (Antonelli, 2007a, b).

It seems more and more necessary to contribute to the evolutionary approach with an explicit analysis, at the firm level, of the determinants of innovation and the role of externalities in the decision process that leads to their (possible) introduction. To do so it is necessary to go back to the Schumpeterian dynamics, where innovation is not the outcome of a random process but the result of the creative response of firms and their intentional pursuit of new technologies made possible by the properties of the system in which the process takes place. In this context, appreciation of the Marshallian roots enables to focus attention on the role of imitation externalities not only in the selective adoption of new technologies but also, and primarily, in their introduction.

\subsection{THE MARSHALLIAN FOUNDATIONS}

The Marshallian legacy can be regarded as one of the basic components of the notion of creative response contingent upon the property of the systems in which firms are embedded that can be elaborated, building upon the essay published by Schumpeter in 1947. 
The theoretical framework that accounts for innovation as an endogenous process that shares the basic characteristic of an emergent system property, and provides an endogenous understanding of the innovation process able to integrate the analysis at the firm level with the appreciation of the role of externalities embedded in the system, finds its origins in the Marshallian legacy. As a matter of fact the Marshallian legacy has been a constant source of inspiration for Schumpeter on which he relied systematically through all his work.

Schumpeter's (1941) essay in honour of Alfred Marshall documents how the basic ingredients of the Marshallian partial equilibrium approach enabled him to go beyond the contraposition of the 1911 book with respect to Leon Walras. In his tribute to Marshall, Schumpeter acknowledges the many contributions of Marshallian legacy to his own understanding of the role of selective competition among heterogeneous firms.

The adaptation of the Marshallian framework enabled Schumpeter to go beyond the limits of the early framework where innovation was explained by the entrepreneurship (Schumpeter, 1911/34) or just rivalry between firms and articulate a fully endogenous explanation of the innovation process (Schumpeter, 1928, 1942). Following this line of enquiry, the Schumpeterian dynamics elaborated in the 1947 essay can be considered a sequential step that builds on the selection process based on the imitation externalities of the Marshallian legacy leading to the identification of a stable equilibrium with the introduction of two critical novelties: i) the creative response of firms caught in out-of-equilibrium conditions; ii) conditional on the availability of appropriate levels of knowledge externalities so as to implement an endogenous process of technological and structural change. In the Schumpeterian approach, equilibrium takes place only when knowledge externalities are not sufficient to support the response of firms and help them become creative.

Appreciation of the Marshallian microeconomic foundations and their integration into the framework elaborated by Schumpeter is indispensable to implement the missing microfoundations of the innovation process of evolutionary economics. The Marshallian model rests on three building blocks: i) exogenous innovations; ii) no appropriability; and iii) imitation externalities. Let us consider them in turn.

\section{Exogenous Innovations}

In the Marshallian framework innovations are the starting point. Marshall acknowledges the important role of changes in the technology of the production process and the organization of firms. Innovations do play a role in the Marshallian framework. They are introduced occasionally and 
randomly, without any causality. Yet their introduction puts the system in motion. The influence of Marshall on the theory of economic development is clear. The role of entrepreneurship is a first attempt to fill the Marshallian gap in the origin of innovations. Schumpeter (1911/34) however does not really provide an endogenous account of the origin and determinants of entrepreneurship. It remains unclear whether the flows of innovations introduced by entrepreneurs and their entry are steady through time and space, or whether they exhibit relevant and systematic changes. As a matter of fact evolutionary models are intrinsically Marshallian as they rely mainly upon the Schumpeter's legacy whereby, following Marshall, innovations are exogenous as they are introduced by entrepreneurs who enter the economic system from outside without any economic causality.

\section{No Appropriability}

According to Marshall, knowledge cannot be appropriated by inventors; rather, it spills freely like information so that everybody is immediately aware of the details of best practice. Perfect access to the best knowledge at each point in time is a key aspect of the notion of 'normal' cost: 'But though everyone acts for himself, his knowledge of what others are doing is supposed to be generally sufficient to prevent him from taking a lower or paying a higher price than others are doing' (Marshall, 1920, V, 3: 199). As a matter of fact both the notions of limited appropriability and knowledge spillover, eventually elaborated by Arrow (1962) and Griliches (1979) respectively, had been introduced long before by Marshall. ${ }^{7}$

\section{Imitation Externalities}

The imitation of exogenous innovations introduced randomly is the focus of the analysis and the engine of the dynamics both in standard evolutionary models and in Marshall. The opportunity to imitate technological and organizational innovations introduced by third parties is the source of major externalities.

The notion of externalities is one of Marshall's most important contributions to economic theory. Externalities can be defined as the effects on efficiency and output of interactions among firms. With the notion of externalities Marshall is able to consider a wide range of interaction effects that take place in an economic system. Pure or technological externalities stem exclusively from interactions and do not require intentional actions of the recipients; pecuniary externalities stem from interactions-cumtransactions, include the purchase of inputs at prices that are lower than in equilibrium conditions and require intentional action of the recipients. 
Marshall considers two types of externality: agglomeration and imitation. Agglomeration externalities have received much attention, while imitation externalities have not.

Agglomeration externalities stem from the increase in the density of firms co-localized. They are both positive and negative: the density of firms favours the reduction of production costs up to a point. Beyond that point negative externalities stemming from congestion costs are larger than positive externalities stemming from co-localization. The interplay between positive and negative agglomeration externalities identifies an optimum size of industrial districts and the equilibrium level of output.

The identification of imitation externalities, as distinct from agglomeration externalities, is a major contribution to understanding the foundations of the Marshallian selection process and its direct impact on the foundations of Schumpeterian dynamics. Moreover, it enables us to appreciate the further distinction between imitation externalities and knowledge externalities.

Imitation externalities consist in the opportunity for imitators to replicate the innovation introduced by the 'inventor'. As such it concerns the incumbent and potential competitors in the same product market. Recent contributions have clarified the role of imitation in head-to-head rivalry in the very same product market (Bloom et al., 2013; Aghion et al., 2015).

Imitation externalities differ from agglomeration externalities and, as mentioned above, have received lesser attention. More specifically, imitation externalities focus on a component of generic agglomeration externalities that stem from the opportunity of co-localized firms to access and share the competences of the most efficient firms. This chapter draws attention to Marshallian imitation externalities.

The notion of imitation externalities articulated by Marshall - and, more specifically, his analysis of their determinants and effects - reveals substantial differences and yet complementarities with Schumpeterian dynamics. They play a crucial role in both. In the former, externalities are a major propeller of the search for a stable equilibrium. In the latter, in contrast - especially in the legacy of Schumpeter (1947a) - they are a major propeller of persistent growth and evolution.

Imitation externalities are at the heart of the Marshallian dynamics that lead to equilibrium. The Marshallian model of competition, in fact, is based upon variety and selection. Marshall assumes that firms are heterogeneous: some firms perform better than others. Selective competition drives the system to generalize the competence of the best-performing firms. The selection process of heterogeneous agents characterizes the Marshallian search for a 'stable' equilibrium. In stable equilibrium the representative firm applies, while in 'temporary' equilibrium imitation 
externalities apply. In Marshall, equilibrium is the result of a competitive process that reduces heterogeneity to homogeneity. ${ }^{8}$ The variety of firms is the cause of the Marshallian imitation externalities. Externalities and variety decline together, along with a competition process - intertwined with a selection process - that reduces variety, and consequently destroys the very origin of externalities. They display their effects along with the selection process and the reduction of heterogeneity to homogeneity. Marshallian imitation externalities are endogenous to the system and intrinsic to the Marshallian search for equilibrium. As such, however, they are bounded.

Marshall assumes that a variety of firms try to produce, enter and exit the marketplace. At each point in time firms are confronted with partial equilibrium that unveils their heterogeneity in terms of production costs. Less efficient firms are sorted out, while more efficient ones can enjoy the benefits of transient rents and increase their size. In the Marshallian process, new entrants and poorer-performing incumbents can imitate freely the best-performing ones. The efficiency of best performing firms spills freely through the system and can be accessed and shared by any other agent. ${ }^{9}$ The imitative entry of new competitors and the imitation of incumbents affect the shifting position of the supply curve that engenders a sequence of lower market prices and larger quantities. The variance of profitability levels shrinks. In the long term the process leads to the eventual identification of the equilibrium price according to which only most efficient firms can survive with normal profits.

Within industrial districts, the least efficient firms, as well as newcomers, enjoy easier access to the factors that account for the superior competence of the most advanced firms: imitation is more effective and absorption costs are lower. Agglomeration increases the opportunities to benefit from the knowledge of more advanced firms: the two types of externality reinforce each other. When the number and the characteristics of firms reach the long-term equilibrium conditions, however, externalities are no longer fed by the changing levels of the output, population and density of firms. Only worst performing firms can benefit from imitation. Most advanced firms are not allowed to introduce innovations so as to further increase their efficiency. The identification of a stable equilibrium stops the endogenous generation of externalities. In equilibrium there is no growth. Growth lasts as long as the selection and imitation process that enables firms to push the allocation of inputs towards their most effective use. Marshallian externalities are endogenous, but bounded.

The Marshallian dynamics of imitation externalities provide the foundations for Schumpeter's path-breaking contribution in 1947. Marshallian and Schumpeterian externalities are much closer and more interdependent 
than currently assumed in the literature. As a matter of fact the limited appropriability of knowledge and its positive consequences in terms of spillover were well known by Alfred Marshall long before their Arrovian codification. In Marshall, however, only less advanced firms can benefit by imitation - from the knowledge spilling from the most advanced firms. In the Schumpeterian tradition, instead, all firms can benefit from knowledge spillover, including the most advanced ones that can use knowledge spilling in the atmosphere as input to generate new knowledge. In the Marshallian process spillover engenders imitation that leads to the identification of a stable equilibrium, while in the Schumpeterian dynamics spillover engenders knowledge externalities that may reinforce the introduction of further innovations. The two notions of imitation externalities and knowledge externalities are highly distinct. They can be considered steps in a sequence where the Schumpeterian notion of creative reaction based on knowledge externalities implements, augments and extends the Marshallian selective search for a stable equilibrium stretching the dynamics of the typical Marshallian endogenous but bounded imitation externalities with self-reinforcing mechanisms.

Schumpeter (1947a) clearly anticipated the notion of knowledge externalities later articulated by Zvi Griliches. Knowledge externalities consist in the opportunity to use the knowledge embodied in an innovation to generate new knowledge. Knowledge externalities are not bound to an industry or a product market, as they apply to a much larger array of products and processes. While imitation externalities benefit laggards only and necessarily, knowledge externalities provide fundament inputs to all agents to innovate. Knowledge externalities are indispensable to keep innovating (Griliches, 1979, 1984).

The Marshallian analysis of the competition process assumes an exogenous variety of firms and a selection process characterized by the exit of the worst performing firms, the growth of the most efficient ones and the entry of new firms. The entry of new firms takes place because of the knowledge externalities that consist in access to the competence of the most efficient ones. At the end of the Marshallian competition, the initial heterogeneous variety disappears and is gradually reduced to homogeneity where only the most efficient firms survive. The representative agent is the result of the process. On closer analysis it is clear that the Marshallian competition process yields the selection of the best performing firms because of the externalities that enable the worst performing firms to imitate the best performing ones. When the selection process comes to an end, however, and the market has been able to reach equilibrium, imitation externalities are no longer available. In Marshall, imitation externalities are endogenous only in so far as out-of-equilibrium conditions prevail. 
When the system reaches equilibrium conditions, no more knowledge externalities are being generated. The Schumpeterian analysis impinges directly upon the Marshallian legacy, but it makes a key change. ${ }^{10}$ In the Schumpeterian approach, in fact, both variety and externalities are fully endogenous. Both are constantly reproduced within the dynamics of the creative reaction. Firms that are able to react creatively generate new variety as well as new technological knowledge. The latter in turn becomes the source of new knowledge externalities (Metcalfe, 2010).

In Schumpeter's 1947 essay variety is no longer an exogenous attribute defined at the onset of the process, as in Marshall; rather, it is an endogenous product. Schumpeterian firms, as opposed to Marshallian firms, are expected to try to change their technology as a consequence of mismatch experienced in the market place. In so doing they re-create variety that is at the same time a determinant and a consequence of the process.

In Business Cycles (1939) Schumpeter retains the Marshallian notion of endogenous externalities. There, externalities are the endogenous result of the concentration of innovative efforts that in turn stem from the exhaustion of investment opportunities and the decline of profitability based upon previous waves of innovation. The concentration of innovative efforts engenders knowledge spillovers that support the innovation process. Once the waves have been introduced, the density of innovation efforts declines and, together with them, the amount of knowledge externalities shrinks. In Business Cycles knowledge externalities are generated within the system and do not stay at given levels: they fluctuate across time and space, as they are at the same time the cause and consequence of creative reactions.

Schumpeter (1941) actually implements the Marshallian notion of endogenous externalities. In Marshall, in fact, externalities are endogenous but cannot increase beyond long-term equilibrium levels. Once the Marshallian selection process has made it possible to reduce (exogenous) variety and identify best practice, the system has reached the maximum possible output and the endogenous provision of externalities stops (Cassata and Marchionatti, 2011). The Schumpeterian process of endogenous creation of knowledge externalities is cyclical but endless, as it is associated with long-term disequilibrium. ${ }^{11}$ The path-breaking contribution of Schumpeter (1947a) relies on both knowledge and imitation externalities. The notion of creative response he articulated can be regarded as a fully fledged evolutionary process based upon the notion of endogenous innovation as the outcome of a creative reaction that takes place in out-ofequilibrium conditions when firms' plans do not meet the actual product and factor market conditions - provided the system is able to support their reaction with the provision of knowledge externalities. 
Like Marshall, Schumpeter assumes that there is a variety of firms. Each firm makes plans based upon its own expectations. It starts the production process; enters its relevant product and factor markets; and may be confronted with unexpected market conditions that engender out-ofequilibrium conditions. The entry of new competitors that rely on imitation externalities, a typical trait of the Schumpeterian dynamics - established since Theory of Economic Development and amplified in Capitalism Socialism and Democracy - is at work also in 'The creative response in economic history' (1947a). Here, however, the distinction between imitation and knowledge externalities applies and displays its powerful effects. Firms try to react: their reaction will be adaptive if no knowledge externalities are available. In this case firms can only move on the existing map of isoquants changing the techniques, but not the technology. The reaction will be creative if knowledge externalities are sufficient to support their innovation efforts. In this second case firms are actually able to introduce innovations that change the map of isoquants.

Schumpeter (1947a) makes two crucial innovations to the Marshallian frame. The first Schumpeterian graft onto the Marshallian frame consists in the notion of reaction. According to the evolutionary frame that builds upon Schumpeter (1947a, 1928), firms can try to react to unexpected mismatch between their plans and related investments, and irreversible commitments and actual conditions of product and/or factor markets. Their reaction will be either adaptive by means of sheer technical changes, consisting in movements of the existing map of isoquants, or creative by means of the introduction of innovations.

The second Schumpeterian graft concerns the appreciation of the role of endogenous knowledge externalities that are generated in the localized context of action in which each firm is embedded. Schumpeter had already made clear earlier that externalities are endogenous to the system. ${ }^{12}$ The quality of the externalities available to each firm is the sorting device that discriminates between passive or adaptive reactions and creative ones. Adaptive reactions consist of simple movements on the existing maps of isoquants: firms are not able to innovate. Creative reactions that lead to the introduction of productivity enhancing innovations are possible only if the access to knowledge externalities and the actual conditions of use of external knowledge support the innovative attempts of firms.

The frame elaborated in Schumpeter (1947a) can be regarded as a fully fledged evolutionary process based upon the notion of innovation as a creative reaction that takes place when firms' plans do not meet the actual product and factor market conditions, provided the system is able to support their reaction with the provision of knowledge externalities. The starting point of the Schumpeterian dynamics is clearly the Marshallian 
representation of the working of competitive markets in the selection process that is expected to lead to the identification of the long-term equilibrium point viewed as a stable attractor (Schumpeter, 1941).

The Schumpeterian dynamics elaborated in the 1947 essay impinge upon the Marshallian dynamics and yet differ from it for four key reasons:

1. Schumpeter makes the distinction between imitation and knowledge externalities. Marshallian agents can only imitate advanced firms. Advanced firms cannot take advantage of their transient competitive advantage to introduce new innovations. Knowledge externalities, instead, make it possible for every firm to introduce productivityenhancing innovations that keep the system in a cost-reducing process.

2. Knowledge externalities are endogenous. They may, in fact, be further reinforced by the increased level of generation of new technological knowledge that is able to reinforce the further creation of endogenous knowledge externalities.

3. In Schumpeter the creative reaction of firms supported by the selfsustained dynamics of knowledge externalities enables the introduction of innovations. Schumpeterian agents exhibit the distinctive characters of entrepreneurship that enable them to try to react to both good and bad performances. In both cases, in fact, they will try to introduce innovations either to contrast their decline and eventual exit or to take advantage of their competitive advantage and increase it with the introduction of new technologies.

4. Out-of-equilibrium conditions are not bound, like in Marshall, but may be self-reinforcing. Innovations are by definition the cause of unexpected changes in product and factor markets.

The Schumpeterian path-dependent dynamics of self-reinforcing mechanisms that may enable the continual creation of knowledge externalities that support the expansion of the generation of new technological knowledge - which in turn leads to both the introduction of productivityenhancing innovations and the creation of new knowledge externalities exhibits all the characteristics and the properties of complex system dynamics (Anderson et al., 1988; Arthur et al., 1997).

At the same time, appreciation of the central role played by the systemic mechanisms underlying the creation of knowledge externalities confirms that, in Schumpeterian dynamics, innovation is fully endogenous and is an emergent property of the system rather than the result of the individual entrepreneurial act (Lane, 2002; Lane et al., 2009). 


\section{NOTES}

1. The outstanding work of Esben Andersen (2009) and Clemence (1989) can be considered among the few exceptions. Schumpeter's 1947 article was reprinted in Clemence (1989: 221-31), together with the companion essay, 'Theoretical problems of economic growth' (Schumpeter, 1947b).

2. See the Appendix in Chapter 4.

3. Careful reading of Nelson and Winter (1982: 211) seems to suggest that firms would change their routines and introduce innovations only as a reaction to adversity: "we assume that if firms are sufficiently profitable they do no "searching" at all. They simply attempt to preserve their existing routines, and are driven to consider alternatives only under the pressure of adversity.' In so doing Nelson and Winter rule out the hypothesis that firms with profits above the average introduce innovations.

4. See Nelson and Winter (1982: 165-6): 'In the orthodox formulation, the decision rules are assumed to be profit-maximizing over a sharply defined opportunity set that is taken as a datum, the firms in the industry and the industry as a whole are assumed to be at equilibrium size, and innovation (if treated at all) is absorbed into the traditional framework rather than mechanically. In evolutionary theory, decision rules are viewed as a legacy from firm's past and hence appropriate, at best, to the range of circumstances in which the firm customarily finds itself, and are viewed as unresponsive, or inappropriate to novel situations or situations encountered irregularly. Firms are regarded as expanding or contracting in response to disequilibria, with no presumption that the industry is "near" equilibrium. Innovation is treated as stochastic and as variable across firms.'

5. Edith Penrose fully anticipated the problem: 'We have no reason whatsoever for thinking that the growth pattern of a biological organism is willed by the organism itself. On the other hand, we have every reason for thinking that the growth of a firm is willed by those who make the decisions of the firm and are themselves part of the firm, and the proof of this lies in the fact that no one can describe the development of any given firm or explain how it came to be the size it is except in terms of decisions taken by individual men' (1952: 808).

6. See Nelson and Winter (1973: 441-2): 'Over time, the technique used by a firm may change as a result of two kinds of search processes, either of which may be triggered when rates of return fall below target levels. One process is internal to the firm and may be identified conceptually with the firm's research and development, operations analysis, and related activities. We assume that these activities turn up possible new techniques that are more likely to be "close" to the current technique (in terms of similarity of input coefficients) than far away. In this sense we have adopted the metaphor of "local" or "incremental" search that is familiar in organization theory and also seems generally consistent with studies of technical change at the firm level. The second type of search process is an imitation mechanism: The firm is more likely to consider a given technique the greater the percentage of current industry output produced with that technique. The possibilities turned up by these search processes are then subjected to a profitability test: Is the alternative technique more profitable, at prevailing prices, than the one currently employed? If the answer is yes, the firm will switch, otherwise not.'

7. Limited knowledge appropriability and the related spillover of proprietary knowledge are at the heart of both the Marshallian and the Schumpeterian dynamics. In the former they engender imitation externalities bounded to less efficient firms. In the latter, instead, they can be used by all firms, including the most advanced ones. For this reason we shall call them, respectively, imitation externalities and knowledge externalities.

8. See Metcalfe (2007a: 10): 'In a famous passage Marshall claims that the tendency to variation is the chief source of progress ... (Marshall, 1920, V, 4, p. 355). This telling phrase captures in a single step the deep evolutionary content of Marshall's thought but "What is meant by this?" The rest of the Principles make clear that variation and progress are connected by a variation cum selection dynamic, Marshall's principle of substitution in which more profitable firms prosper at the expense of weaker brethren. 
Outcomes are tested in the market so that "society substitutes one undertaker for another who is less efficient in proportion to his charges" (Marshall, 1920, V, 3, p. 341). Indeed, in introducing a discussion of profit in relation to business ability, Marshall is quite explicit that this principle of substitution is a "special and limited application of the law of "the survival of the fittest" (Marshall, 1920, VI, 7, p. 597). Furthermore, innovation is inseparable from the competitive process. For the advantages of economic freedom "are never more strikingly manifest than when a business man endowed with genius is trying experiments, at his own risk, to see whether some new method or combination of old methods, will be more efficient than the old" (Marshall, 1920, V, 8, p. 406). The relation runs two ways and mutually reinforces the links between free competition and business experimentation.'

9. See Ravix (2012: 53, quoting Marshall, 1920, VI, VII, 1, p. 496): 'In Marshall, entry-exit appears in different contexts. For instance, economic change leads to the distinction between "those who open out new and improved methods of business, and those who follow beaten tracks".'

10. The first attempt to integrate the Marshallian externalities into the analysis of innovation as an out-of-equilibrium process dates from Schumpeter's essay 'The instability of capitalism', where the role of externalities in the innovation process is clearly identified: 'What matters for the subject of this study is merely the essentially discontinuous character of this process, which does not lend itself to description in terms of a theory of equilibrium. But we may conveniently lead up to this by insisting for the moment on the importance of the difference between this view and what I have called the received one. Innovation, unless it consists in producing, and forcing upon the public, a new commodity, means producing at smaller cost per unit, breaking off the old "supply schedule" and starting on a new one. It is quite immaterial whether this is done by making use of a new invention or not for, on the one hand, there never has been any time when the store of scientific knowledge had yielded all it could in the way of industrial improvement, and, on the other hand, it is not the knowledge that matters, but the successful solution of the task sui generis of putting an untried method into practice - there may be, and often is, no scientific novelty involved at all, and even if it be involved, this does not make any difference to the nature of the process. And we should not only, by insisting on invention, emphasize an irrelevant point irrelevant to our set of problems, although otherwise, of course, just as relevant as, say, climate-and be thereby led away from the relevant one, but we should also be forced - to consider inventions as a case of external economies. Now this hides part of the very essence of the capitalist process. This kind of external economies - and, in fact, nearly every kind, even the trade journal must, unless the product of collective action, be somebody's business - characteristically comes about by first being taken up by one firm or a few-by acting, that is, as an internal economy. This firm begins to undersell the others, part of which are thereby definitely pushed into the background to linger there on accumulated reserves and quasi-rents, whilst another part copies the methods of the disturber of the peace. That this is so, we can see every day by looking at industrial life; it is precisely what goes on, what is missing in the static apparatus and what accounts both for dissatisfaction with it and for the attempts to force such phenomena into its cracking frame instead of, as we think it natural to do, recognizing and explaining this as a distinct process going on along with the one handled by the static theory' (Schumpeter, 1928: 378-9; italics added).

11. See Schumpeter (1941: 242-3): 'A still more significant point comes into view if we pass from the distinction static-dynamic to the distinction stationary-evolutionary. Marshall put up, somewhat regretfully as it seems, with the static nature of his apparatus but he disliked the stationary hypothesis to the point of overlooking its usefulness for some purposes. His thought ran in terms of evolutionary change - in terms of an organic, irreversible process. And something of the flavor of it he imparted to his theorems and concepts and still more to the factual observations with which he presented them. I do not think that the theory of evolution at the back of them was satisfactory. No schema can be that does not go beyond an automatic expansion of markets - an expansion not 
otherwise motivated than by increase of population and by saving - which then induces internal and external economies that in turn are to account for further expansion. But still it was a theory of evolution, an important development of Adam Smith's suggestions, and greatly superior to what Ricardo and Mill had to offer on the subject.'

12. See Schumpeter (1928: 379$)$, as quoted in note 10 . 